\title{
Magamp Post Regulation for Flyback Converter
}

\author{
Chau-Chun Wen and Chern-Lin Chen \\ Power Electronics Laboratory \\ Department of Electrical Engineering \\ National Taiwan University \\ Taipei, Taiwan
}

\author{
Wei Chen and Jian Jiang \\ Delta Power Electronics Center \\ 238 Minxia Road, CIMIC Industry Zone \\ Pudong, Shanghai, 201209, China
}

\begin{abstract}
In this paper, a new magamp technique for flyback converters is proposed. Operation principle of the proposed approach is described and design guidelines are provided. Experimental verifications on a 50W two-output flyback converter are conducted. Recordings show that the proposed approach is effective and voltage regulation of the auxiliary output is excellent.
\end{abstract}

\section{INTRODUCTION}

The magnetic amplifier (magamp) post regulator had been widely used in multiple output power supplies for many years. Compared with other post regulation schemes, magamp technique is one of the most reliable and cost effective solutions. Magamp post regulators also have the advantages of high efficiency, low part-count, high power density and robustness. Especially for high-current post-regulated output applications, the magamp methods become the most attractive solutions. Since for high output current applications, the efficiency of linear post-regulators is extre mely low and couldn't be accepted by the multiple output switching mode power supplies with compact size and high efficiency requirements. For many years, the magamp techniques are mostly applied in forward type converters. Fig. 1 shows the diagram of PWM-controlled forward converter with a magamp output.

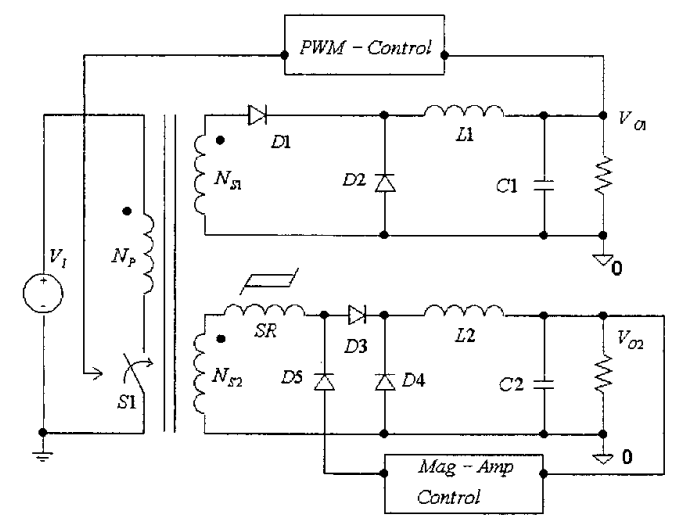

Fig. 1. The diagram of PWM-controlled forward converter with a magamp output
The research works on the use of magamp for forward converters are widely reported for last decades. The resetting methods, small signal modeling and stability analysis are investigated in $[1][2][3][4]$. The design guidelines, limitations and considerations of the magamp regulators are also discussed in [5][6][7]. In some low cost applications, flyback converters are more attractive than forward converters, especially under $100 \mathrm{~W}$ applications. A time-sharing magamp technique for a flyback converter is presented in [8]. Two distinct output voltages are developed from a single output winding. The method is simple and effective. But the main output for PWM feedback is restricted to the output with higher voltage, even with light rated output current. In this paper, a new magamp technique for flyback converters with multiple output windings is proposed. The detail operation principle will be clearly explained first. For the practical design issues, some design guidelines and considerations for magamp in flyback converters are also proposed next. At last, experimental verifications on a $50 \mathrm{~W}$ two-output flyback converter are conducted.

\section{OPERATION PRINCIPLE}

Fig. 2 shows the diagram of PWM-controlled flyback converter with a magamp output.

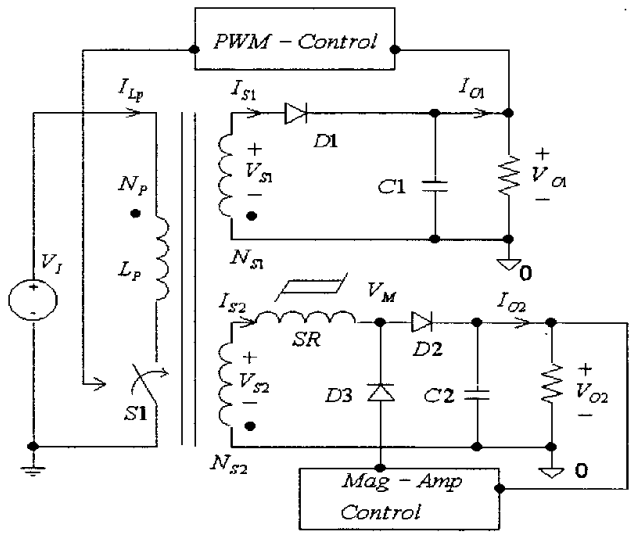

Fig. 2. The diagram of PWM-controlled flyback converter with a magamp output 
It is obvious that flyback topology is simpler and has less part-count than forward topology. In forward converter, the secondary outputs of main transformer could be viewed as voltage sources. As the saturable reactor of magamp regulator is in blocking state, the power of main output is supplied from input voltage by the main transformer. When the saturable reactor becomes saturated, the power is supplied to the main output and auxiliary output simultaneously. Due to the PWM feedback control and the magamp feedback control, the regulation of main output and auxiliary output can be achieved respectively. The configuration of magamp regulator in flyback converter seems the same as that in forward converter. But the operation principles are completely different. Fig. 3 shows some key waveforms in flyback converter with a magamp regulator.

Fig. 4 shows different operation states in flyback converter with a magamp regulator.

(a)

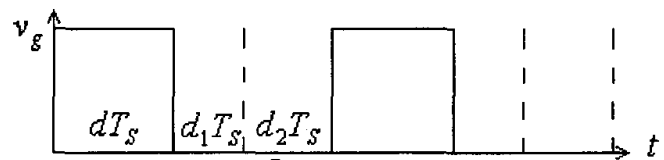

(b)

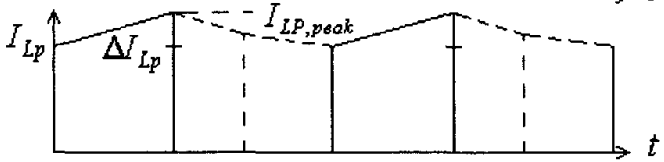

(c)

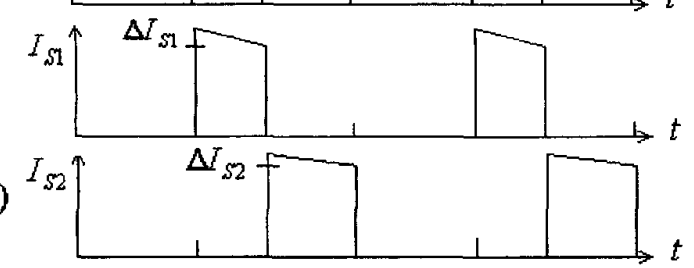

(e)
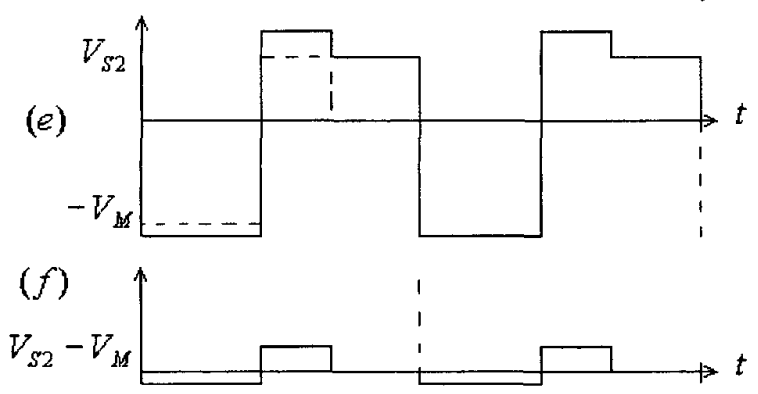

Fig. 3. Some key waveforms in flyback converter with a magamp regulator (referring to Fig. 4)

( $v_{g}$ is the gate driving signal of main switch $S 1$ ) (a)

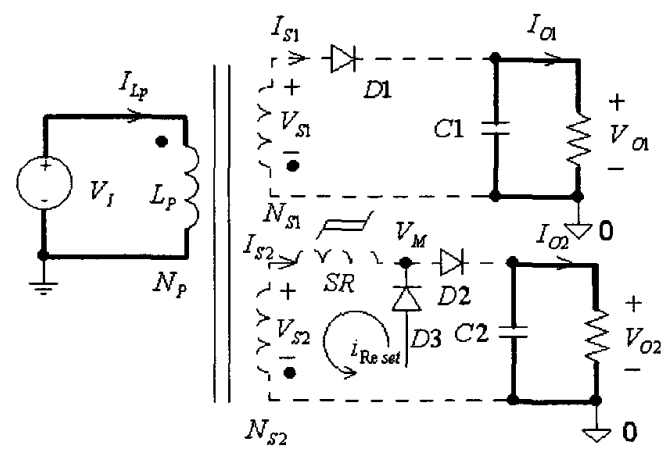

(b)

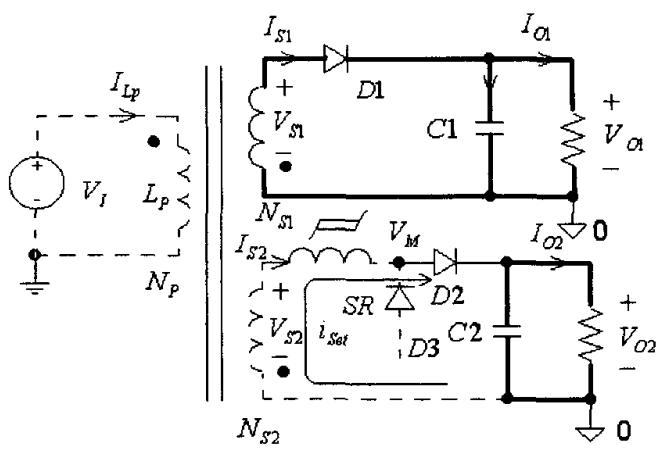

(c)

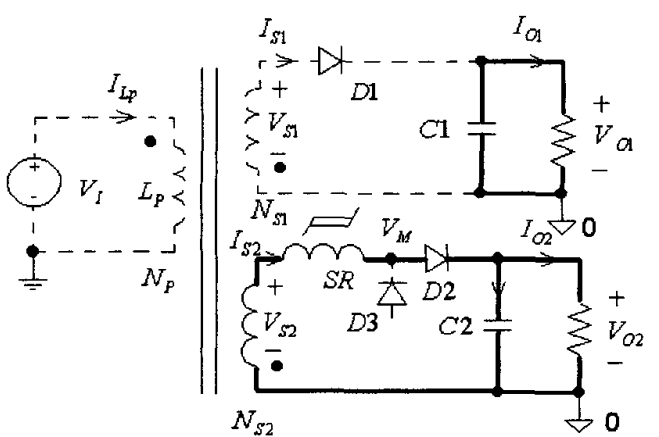

Fig. 4. The operation states in flyback converter with a magamp regulator
(a) time period during $d T_{S}$
(b) time period during $d_{I} T_{S}$
(c) time period during $d_{2} T_{S}$

In the time period $d T_{S}$, the switch $S I$ is on and the input voltage $V_{I}$ charges the magnetizing inductance $L_{P}$, here $d$ is the turn-on duty cycle and $T_{S}$ is the switching period. In flyback converter, the main transformer is not only a common transformer but also an inductor to supply the energy to the outputs. At this period, the saturable reactor is reset by the voltage difference between the reverse secondary winding voltage $V_{S 2}$ and the magamp controlled voltage $V_{M}$, as shown in Fig. 4 (a). In the time period $d_{1} T_{S}$, as shown in Fig. 4(b), the switch is off and the magnetizing 
inductance discharges the energy to the main output $V_{O I}$. During this time period, the diode $D I$ is on and the secondary winding voltage $V_{S I}$ is clamped at the main output voltage $V_{O I}$. The saturable reactor $S R$ is on blocking state and is set with the voltage difference between the secondary winding voltage $V_{S 2}$ and the auxiliary output voltage $V_{O 2}$. Ideally the stored energy in the main transformer is supplied to the main output only. As soon as the saturable reactor $S R$ is saturated as shown in Fig. 4(c), the diode $D 2$ becomes on and the secondary winding $V_{S 2}$ is clamped at the auxiliary output voltage $V_{O 2}$. Since the reflected voltage on the winding voltage $V_{S I}$ is lower than the main output voltage $V_{O I}$, the diode $D I$ becomes reverse bias and turns off. As a result, the stored energy of the main transformer is only transferred to the auxiliary output during the time period $d_{2} T_{S}$ ideally. At the end of the switching period, the main switch turns on again and the saturable reactor $S R$ is reset for next switching period.

According to the above description, there are two major operation differences between flyback converters and forward converters with magamp applications. The first is the main transformer could be viewed as a current source and the secondary winding voltages is depended on the voltages clamped by the outputs. This is due to the original characteristic of the main transformer in flyback converter, which is an energy-storage inductor. The second, the energy is supplied to the main output and auxiliary output in different time intervals. This is time sharing approach on the current of main transformer during the main switch off time. Since these differences, the design guidelines and considerations of magamp regulator in flyback converters are different from those of the forward converters and will be discussed in next section.

\section{DESIGN GUIDELINES AND CONSIDERATIONS}

In this section, we will discuss the practical design of flyback converter with a magamp regulator. The design equations and guidelines could be extended to multiple magamp regulation applications. It is assumed that the flyback converter is designed in continuous-current mode. The main design specifications are as follows:

$\begin{array}{lc}\text { Input range: } & V_{l, \min } \sim V_{I, \max } \\ \text { Output power: } & P_{O} \\ \text { Main output rated voltage: } & V_{O I} \\ \text { Main output rated current: } & I_{O I} \\ \text { Auxiliary output rated voltage: } & V_{O 2} \\ \text { Auxiliary output rated current: } & I_{O 2}\end{array}$

\section{a. Main Transformer:}

The design procedure of the flyback transformer is the same as the design of inductor. We choose a proper core by winding area and power handling capability. Considering continuous current mode operation, the swing range of the magnetizing current $\Delta I_{L p}$ can be determined. The maximum duty of the main switch $d_{\max }$ is selected under the minimum input voltage $V_{l, \min }$. The duty cycle $d$ shouldn't be over $50 \%$ to prevent the sub-harmonic oscillations if the current mode control scheme is selected. Then, we can easily find the magnetizing inductance $L_{P}$ of the primary winding $N_{P}$ by the Faraday's law:

$$
L_{P}=\frac{V_{I, \min } \cdot d_{\max } \cdot T_{S}}{\Delta J_{L p}}
$$

To avoid the core from saturation, the maximum magnetic flux density $B_{\max }$ must be determined. Considering the fringing effects, the air gap $\ell_{\mathrm{g}}$ is properly chosen. The turns of the primary winding $N_{P}$ can be obtained from the Ampere's law:

$$
B_{\max } \cdot\left(\frac{\ell_{g}}{\mu_{0}}+\frac{\ell_{C}}{\mu}\right)=N_{P} \cdot\left(I_{L p, \max }+\frac{\Delta I_{L p}}{2}\right),
$$

where $\ell_{C}$ is the length of core.

Assuming the energy transferring efficiency is perfect, the maximum average magnetizing current $I_{L p, \max }$ can be obtained in (3):

$$
I_{L p, \max }=\frac{P_{O}}{V_{I, \min } \cdot d_{\max }}
$$

Of course, the wire current density and winding window area have to be taken into account in determining $N_{P}$.

To determine the secondary windings $N_{S 1}$ and $N_{S 2}$, the condition (4) must be satisfied in flyback converter with a magamp regulator.

$$
\frac{V_{O 1}}{N_{S 1}}>\frac{V_{O 2}}{N_{S 2}}
$$

Here, we assume the output diodes are ideal, i.e. the forward voltage drop of diodes is zero. From the volt-sec balance rule of the main transformer, we have (5) and (6).

$$
\begin{gathered}
V_{I} \cdot d=\frac{N_{P}}{N_{S 1}} \cdot V_{O 1} \cdot d_{1}+\frac{N_{P}}{N_{S 2}} \cdot V_{o 2} \cdot d_{2} \\
d+d_{1}+d_{2}=1
\end{gathered}
$$

From (4), (5) and (6), we may have (7) and (8) for selecting the secondary windings $N_{S I}$ and $N_{S 2}$ :

$$
N_{S 1}<\frac{N_{P} \cdot V_{O 1} \cdot(1-d)}{V_{I} \cdot d}
$$




$$
N_{S 2}>\frac{N_{P} \cdot V_{O 2} \cdot(1-d)}{V_{I} \cdot d}
$$

As long as $N_{S l}$ and $N_{S 2}$ are determined, the duty cycles $d$, $d_{1}$ and $d_{2}$ have to be recalculated with (5), (6) and the following equations also need to be satisfied:

$$
\begin{gathered}
I_{O 1}=\frac{\left(2 I_{L P, p e a k}-\frac{N_{P}}{N_{S 1}} \frac{V_{O 1}}{L_{P}} d_{1} T_{S}\right) \cdot d_{1}}{2 \cdot \frac{N_{S 1}}{N_{P}}} \\
I_{O 2}=\frac{\left(2 I_{L P, p e a k}-2 \cdot \frac{N_{P}}{N_{S 1}} \frac{V_{O 1}}{L_{P}} d_{1} T_{S}-\frac{N_{P}}{N_{S 2}} \frac{V_{O 2}}{L_{P}} d_{2} T_{S}\right) \cdot d_{2}}{2 \cdot \frac{N_{S 2}}{N_{P}}}
\end{gathered}
$$

where $I_{L P, p e a k}$ is the peak value of magnetizing current.

From (5), (6), (9) and (10), it can be found that the duty cycles $d, d_{1}$ and $d_{2}$ are effected by both the load conditions and the magnetizing inductance.

\section{b. Output Capacitor:}

There are two major considerations in design of output capacitors. The first is the capacitor ripple current that is related to the lifetime of capacitor. The second is the output ripple voltage that is general specification for output requirements. Assuming the current ripples $\Delta I_{L p}, \Delta I_{S 1}$ and $\Delta I_{S 2}$ are small and neglected, the root-mean-square currents of capacitor ripple currents for each outputs $I_{C I, r m s}$ and $I_{C 2, r m s}$ are as follows:

$$
\begin{gathered}
I_{C 1, m s}=I_{O 1} \cdot \sqrt{\frac{1-d_{1}}{d_{1}}} \\
I_{C 2, m s}=I_{O 2} \cdot \sqrt{\frac{1-d_{2}}{d_{2}}}
\end{gathered}
$$

The output-ripple voltages $\Delta V_{O 1}$ and $\Delta V_{O 2}$ can be obtained from (13) and (14).

$$
\begin{gathered}
\Delta V_{o 1}=\frac{I_{O 1} \cdot T_{S} \cdot\left(1-d_{1}\right)}{C_{1}} \\
\Delta V_{O 2}=\frac{I_{O 2} \cdot T_{S} \cdot\left(1-d_{2}\right)}{C_{2}}
\end{gathered}
$$

\section{c. Saturable Reactor:}

The major considerations and limitations for saturable reactor of magamp regulator in flyback converters are almost the same as in forward converters. Fig. 5 shows the BH curve of the saturable reactor.

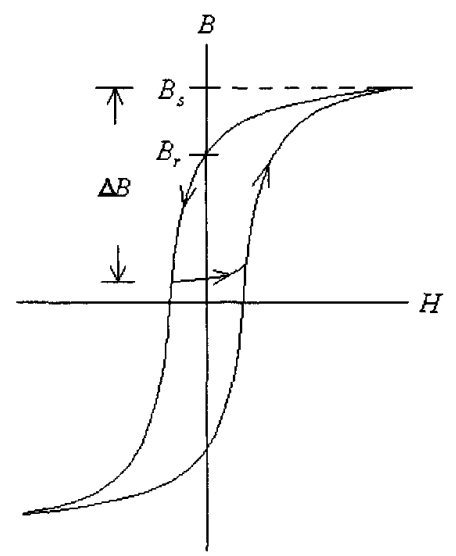

Fig. 5. The B-H curve of saturable reactor

Before we select a proper core, the maximum blocking volt-second area must be determined first. The condition of maximum blocking volt-second area is happened at the heavy main output load and the light auxiliary output load. The input voltage will be the maximum input voltage $V_{I, \max }$ in continuous current mode (CCM) or the boundary input voltage $V_{I, b o u n d a r y}$ in discontinuous current mode (DCM) boundary condition. The following equations determine the maximum duty of $d_{1, \max }$ :

$$
d_{1, \text { max }}=\frac{V_{I, \text { max }} \cdot \frac{N_{S 1}}{N_{P}}}{V_{O 1}+V_{I, \text { max }} \cdot \frac{N_{S 1}}{N_{P}}} \quad \text { at } \mathrm{CCM}
$$

or

$$
d_{1, \max }=1-\frac{\sqrt{2 V_{O 1} \cdot I_{O 1} \cdot \frac{L_{P}}{T_{S}}}}{V_{1, \text { boundary }}} \quad \text { at DCM }
$$

The maximum blocking volt-sec area can be found in (17).

$$
d_{1, \max } \cdot T_{S} \cdot\left(\frac{N_{S 2}}{N_{S 1}} \cdot V_{O 1}-V_{O 2}\right)=N \cdot A_{e} \cdot \Delta B_{S R, \max },
$$

where $A_{e}$ : the effective core section area of saturable core; $\Delta B_{S R, \max }$ : the maximum swing range of flux density in saturable core;

$N$ : the turns of saturable reactor.

As in the design of satruable reactor in forward converters, one can choose a proper core by the area product equation when the maximum blocking volt-second area is known. Considering core loss, core size and resetting current, one can optimize the design of saturable reactor after some iteration. As in [9], if one considers the extreme loading conditions, such as auxiliary output shutdown or short circuit, 
the maximum blocking volt -second area would be even more.

Due to squareness of saturable core, saturated inductance and reverse recovery of output rectifier [6], these cause delay in a switching period. In forward converters, this delay reduces the maximum effective duty cycle of magamp regulator. But in flyback converters, this delay causes the minimum output power requirement in the main output. This requirement is found at heavy auxiliary output load, light main output load and low line input condition. Under this condition, the peak magnetizing current $I_{L p \text {.Peak }}$ is:

$$
I_{L p, p e a k}=\frac{V_{O 2} \cdot I_{O 2}}{V_{I, \min } \cdot\left(1-d_{2}\right)}+\frac{V_{I, \min } \cdot T_{S} \cdot\left(1-d_{2}\right)}{2 \cdot L_{P}}
$$

To simplify the derivation, we assume the main output is at open load condition, the converter is still in continuous current mode and the delay time is small compared with switching period. The duty $d_{2}$ can be obtained from (19):

$$
d_{2}=\frac{V_{l, \min } \cdot \frac{N_{S 2}}{N_{P}}}{V_{O 2}+V_{I, \min } \cdot \frac{N_{S 2}}{N_{P}}}
$$

Assuming that the effect of reverse recovery is neglected, the delay time $T_{\text {delay }}$ caused by the squareness and saturated inductance $L_{S}$ of saturable reactor is obtained as follows:

$$
T_{\text {delay }}=\frac{N \cdot A_{e} \cdot\left(B_{s}-B_{r}\right)+L_{S} \cdot \frac{N_{P}}{N_{S 2}} \cdot I_{L p, p e a k}}{\frac{N_{S 2}}{N_{S 1}} \cdot V_{O 1}-V_{O 2}},
$$

where $B_{s}$ is saturation flux density and $B_{r}$ is residual flux density. Then we may have the minimum main output power requirement $P_{O 1, \min }$ :

$$
P_{o 1, \text { min }}=\frac{N_{P}}{N_{S 1}} \cdot I_{L p, \text { peak }} \cdot V_{O 1} \cdot \frac{T_{\text {delay }}}{T_{S}}
$$

\section{N. EXPERIMENTAL RESULTS}

A 50W two-output flyback converter is designed to verify the operation principle. The designed parameters are listed as follows:

$\begin{array}{ll}\text { Input range: } & 90 \mathrm{Vac} \sim 270 \mathrm{Vac} \\ \text { Main output: } & 5 \mathrm{~V} / 0 \mathrm{~A} \sim 5 \mathrm{~A} \\ \text { Auxiliary output: } & 12 \mathrm{~V} / 0 \mathrm{~A} \sim 2 \mathrm{~A}\end{array}$

The turns of main transformer on primary side is 37 turns and the magnetizing inductance is $650 \mathrm{uH}$. The secondary windings are 2 and 8 turns for $5 \mathrm{~V}$ and $12 \mathrm{~V}$ outputs respectively. The core number is EI33 from TDK. The saturable reactor is 6 turns and core number is MP1506 from Allied Signal. The dummy load on main output is $2.5 \mathrm{~W}$ and the measured efficiency is $70.16 \%$ at low line input and full load condition. There are two commonly used methods in control circuit, current mode reset and voltage mode reset [1][6]. Current mode reset is the most used approach since it does not require a negative source for the control circuit. In the experimental circuit, the current mode reset control is used. Fig. 6 shows some key waveforms.

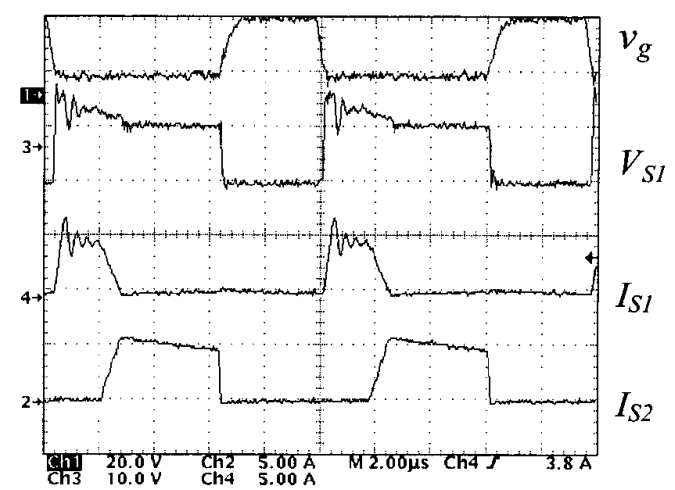

(a)

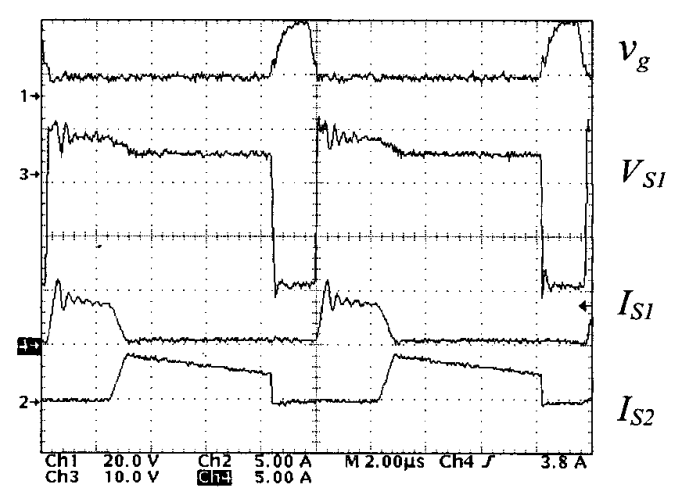

(b)

Fig. 6. Some key waveforms in 50W two-output flyback converter

(a) Measurement at $90 \mathrm{Vac}$ input and heavy load condition,

(b) Measurement at $270 \mathrm{Vac}$ input and heavy load condition

The time-sharing characteristic in output currents is obvious in Fig. 6. Fig. 7 shows regulations of main output and auxiliary output respected to the load ranges. The data show well regulation for all outputs. The experimental results show the effectiveness of magamp regulator in flyback converter applications.

\section{v. CONCLUSIONS}

In this paper, we briefly discuss the operation of the magamp post regulator in flyback converters with multiple output windings. The circuit of magamp regulator looks alike in the forward converters. But the operation principle is 
totally different. The output of the main transformer in flyback converter is viewed as current sources. The energy is supplied to each output windings by time-sharing approach. Some design guidelines and considerations are provided. The major differences when design a magamp regulator in between flyback converters and forward converters are as follows:

a. The design procedure of flyback transformer is similar to the traditional procedure. The requirement for multiple secondary windings is that $(22)$ need to be satisfied:

$$
\frac{V_{O 1}}{N_{S 1}}>\frac{V_{O 2}}{N_{S 2}}>\ldots
$$

b. Due to time-sharing in transformer output current, the time period for each output will be reduced. This effect will increase the root-mean-square currents in output loops and cause the increments in the rating of components and power losses. It becomes worse as the number of mag-amp regulators is increased.

c. The duty cycles $d, d_{l}$ and $d_{2}$ are related not only input and output voltages but also the load conditions and the magnetizing inductance of main transformer.

d. Due to the squareness of the core material and the saturated inductance, it causes time delay in switching period of saturable reactor. In forward converters, this effect introduces the limitation on the effective duty cycle of magamp regulator. In flyback converters, the time delay will cause a minimum output power requirement in main output.

Finally, some experimental results on a $50 \mathrm{~W}$ two-output flyback converter are shown the effectiveness of magamp regulator in flyback converters.

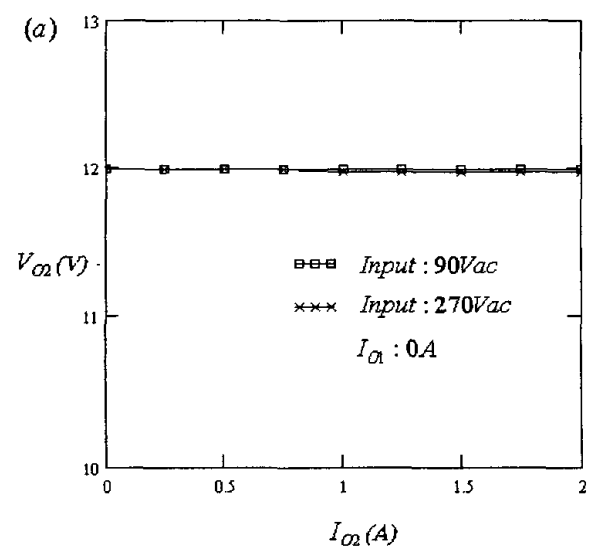

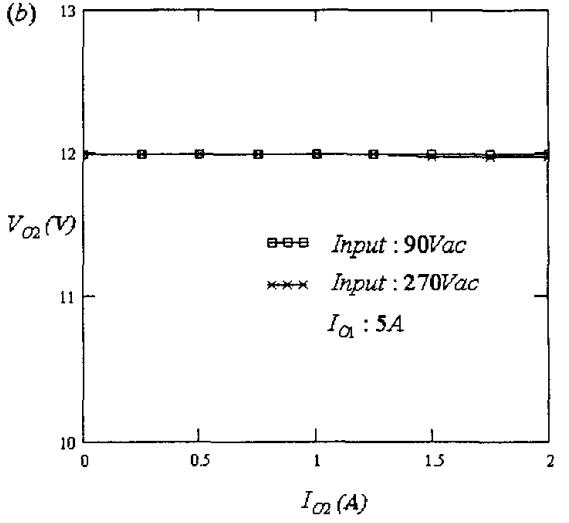

Fig. 7. Load regulations of auxiliary output $\mathrm{V}_{\mathrm{O} 2}$ for different line inputs at (a) light load condition of main output

(b) heavy load condition of main output

\section{REFERENCES}

[1] Milan M. Jovanovic, Laszio Huber, “ Small-Signal Modeling of Magamp PWM Switch", Applied Power Electronics Conference, pp. 922-928, 1997.

[2] Audrey M. Urling, Thomas G. Wilson, Harry A.Owen Jr, Gordon W. Cromwell, Joe Paulakonis, " Modeling the Frequency-Domain Behavior of Magnetic-Amplifer-Controlled High-Frequency Switched-Mode Power Supplies", Applied Power Electronics Conference, pp. 19-31, 1987.

[3] D. Y. Chen, J. Lee, C. Jamerson, "A Simple Model Predicts Small-Signal Control Loop Behavior of Magamp Post Regulator", High Frequency Power Conversion Conference, pp. 69-84, 1988.

[4] J. Lee, D. Y. Chen, Y. P. Wu, C. Jamerson, "Modeling of Control Loop Behavior of Magamp Post Regulators", IEEE International Telecommunications Energy Conf. (INTELEC) Proc., Paper 20.1, 1989.

[5] Paul Kotlarewsky, "Beyond the Limitation of Reset Control and Square Loop of Materials for Mag-Amp Post Regulators", High Frequency Power Conversion Conference, pp. 129-139, 1991.

[6] Robert M. Tedder, "Limitations of the Magamp Regulator and an Improved Magamp Choke Design Procedure", Applied Power Electronics Conference, pp. 109-117, 1988.

[7] Robert M. Tedder, "Effects of Converter Type, Reset Method and Core Material on Magamp Regulator Performance", Applied Power Electronics Conference, pp. 391-400, 1989.

[8] O.N. Nelson, "Time share mag amp", High Frequency Power Conversion Conference, pp.49-54, 1988.

[9] J. Lee, D. Y. Chen, C. Jamerson, "Magamp Post Regulators-Practical Design Considerations to Allow Operation Under Extreme Loading Conditions", IEEE Transactions on Power Electronics, Vol. 5, No. 1, pp.69-76, 1990. 